\title{
Engajamento e Sucesso na Transição para o Trabalho: Estudo com Medidas Repetidas
}

\author{
Alexandre Yomatsu de Paula Okumoto ${ }^{1}$ \\ ${ }^{1}$ Universidade Federal do Triângulo Mineiro, MG, Brasil. \\ Marina Cardoso de Oliveira ${ }^{1}$ \\ ${ }^{1}$ Universidade Federal do Triângulo Mineiro, MG, Brasil.
}

\author{
Lucy Leal Melo-Silva ${ }^{2}$ \\ ${ }^{2}$ Universidade de São Paulo, SP, Brasil. \\ Maria do Céu Taveira ${ }^{3}$ \\ ${ }^{3}$ Universidade do Minho, Braga, Portugal.
}

Resumo: O engajamento com a carreira tem se mostrado um bom preditor de resultados positivos associados ao desenvolvimento profissional e ao sucesso na carreira. É crescente o interesse em estudar as relações entre o engajamento e o sucesso no contexto da transição universidade-trabalho. Esta investigação recorreu ao delineamento prospectivo com medidas repetidas para analisar as variações do engajamento com a carreira, durante e após a conclusão da graduação; além de verificar o poder preditivo sobre o sucesso na transição universidadetrabalho. Esta pesquisa contou com 108 participantes, de diferentes regiões do Brasil e áreas de formação, que responderam ao caderno de pesquisa durante o último ano acadêmico e após a conclusão dos estudos. Foram realizadas análises descritivas e de regressão que demonstraram que o engajamento com a carreira, medido após a graduação, e o tempo de conclusão da graduação foram os melhores preditores para explicar os indicadores de sucesso na transição universidade-trabalho. Ademais, os resultados sugeriram que engajamento com a carreira sofre variações em função do tempo. Os resultados podem ser úteis para planejar intervenções de carreira para universitários e recém-formados que vivenciam a transição universidade-trabalho.

Palavras-chave: Engajamento com a carreira, Desenvolvimento profissional, Sucesso profissional.

\section{Engagement and Success during Transition to Work: Repeated Measures Study}

\begin{abstract}
Career engagement has shown to be a good predictor of positive results associated with career development and success. For this reason, the interest in studying career engagement and career success during university-to-work transition is growing. This study used a prospective design with repeated measures to analyze the career engagement variations during and after graduation, and to verify its predictive power on university-to-work success. This research included 108 participants from several backgrounds and regions of Brazil, who responded to the survey during their last college year and after completing studies. We conducted descriptive and regression analyses, which demonstrated that career engagement measured after graduation and time of conclusion are the best predictors to explain variations in university-to-work success. Besides, the results suggest that the career engagement is not a stable trait, varying over time. The results can be useful to plan interventions for college students and newly graduates who experience university-to-work transition.
\end{abstract}

Keywords: Career engagement, Professional development, Occupational success. 


\title{
Compromiso y Éxito en la Transición al Trabajo: Estudio con Medidas Repetidas
}

\begin{abstract}
Resumen: El compromiso con la carrera, ha sido un buen predictor de resultados positivos asociados con el desarrollo y éxito profesional. Por eso, hay un interés creciente por estudiar las relaciones entre el compromiso y el éxito en el contexto de la transición universidadtrabajo. Esta investigación utilizó el diseño prospectivo con medidas repetidas, y tuvo como objetivo analizar las variaciones de la participación profesional durante y después de la graduación, y verificar su poder predictivo sobre el éxito en la transición universidad-trabajo. En la investigación participaron 108 participantes de diversas áreas de capacitación y regiones do Brasil que respondieron al cuaderno de investigación durante el último año académico y después de terminar sus estudios. Se realizaron análisis descriptivos y de regresión que demostraron que el compromiso con la carrera, medido después de la graduación, y el tempo de finalización fueron los mejores predictores para explicar los indicadores de éxito en la transición universidad-trabajo. Además, los resultados sugieren que la participación profesional varía con el tiempo. Los resultados pueden ser útiles para diseñar intervenciones para estudiantes universitarios y graduados universitarios que experimentan la transición universidad-trabajo.
\end{abstract}

Palabras clave: Compromiso con la carrera, Desarrollo profesional, Éxito profesional.

\section{Introdução}

Nas duas primeiras décadas dos anos 2000, cresceu o número de estudantes que ingressaram e concluíram o ensino superior no Brasil e no mundo. Conquistar uma carreira bem-sucedida faz parte dos objetivos de boa parte das pessoas, sobretudo daquelas que concluem esse nível educacional. Porém, a inserção profissional das pessoas com ensino superior, que já era preocupante antes da pandemia do coronavírus (Nora, 2017), agravou-se ainda mais em decorrência das crises sanitária, econômica, social e política.

Dados de organizações internacionais sinalizam que os jovens estão entre os mais afetados pela pandemia. De acordo com a Organização Internacional do Trabalho (OIT, 2020), os impactos podem deixar uma geração perdida caso não sejam realizados investimentos em orientação e criação de postos de trabalho para as juventudes em início de carreira. Assim, pensar a empregabilidade e o sucesso dos recém-formados no processo de transição para o trabalho deve fazer parte das discussões e proposições para o desenvolvimento econômico e sustentável da sociedade (Baluku et al., 2021).

Até o final do século XX e início deste século, esperava-se que os recém-formados do ensino superior conseguissem, logo após a conclusão da graduação, encontrar um trabalho relacionado com a área de formação e com seus objetivos individuais, além de se adaptarem ao papel de trabalhador (Wendlandt \& Rochlen, 2008). Contudo, o cenário de mudanças vertiginosas, de instabilidades e de escassez de oportunidades, como o que se apresentou nas duas primeiras décadas do século XXI, tornou o processo de transição universidade-trabalho mais crítico para os recém-formados (Masdonati, Massoudi, Blustein, \& Duffy, 2021). Nesse sentido, desafios estão colocados para os serviços de carreira com o objetivo de preparar os universitários e recém-formados para a gestão da carreira em um mundo do trabalho cada vez mais dinâmico e imprevisível.

Com efeito, sabe-se que a transição da universidade para o mercado de trabalho é um processo alargado no tempo, que se inicia durante a graduação e finaliza com a adaptação ao papel de trabalhador. Nesse sentido, Vieira, Caires e Coimbra (2011) sintetizam três grandes momentos que caracterizam a dinâmica do processo de transição da universidade para o mercado de trabalho. Para esses autores, antes do início do exercício profissional, o percurso formativo tende a impulsionar o engajamento dos estudantes. Quando os graduados optam por dar início à atividade profissional, o engajamento no processo de procura por uma atividade remunerada se fortalece. Após a conquista de uma posição profissional remunerada, 
os recém-formados direcionam seu engajamento para atividades que promovam a adaptação ao trabalho.

Vieira et al. (2011) ressaltam que, diante das inúmeras movimentações que ocorrem entre os espaços formativos e laborais, é importante considerar a dinâmica e a interdependência entre os diferentes momentos da carreira dos universitários e recém-graduados. Por sua característica processual, não existe uma referência única para caracterizar o tempo de duração da transição. Por outro lado, Baluku et al. (2021) ponderam que a rapidez com que os recém-formados conseguem se inserir profissionalmente após a conclusão dos estudos é essencial para o progresso de carreira subsequente. Assim, torna-se importante considerar o tempo de conclusão da graduação como uma variável que influencia a percepção e a vivência de sucesso na transição para o trabalho (Oliveira, Detomini, \& Melo-Silva, 2013).

Considerando os argumentos apresentados anteriormente, para explicar o sucesso na carreira durante a transição universidade-trabalho é preciso adotar uma visão multicausal, na qual tanto fatores contextuais quanto individuais se interrelacionam e contribuem para a conquista de resultados associados ao sucesso na carreira (Masdonati et al., 2021). Estudos mostram que em um primeiro momento, os universitários têm a expectativa de que a transição seja bem-sucedida objetivamente, atendendo às necessidades materiais e expectativas sociais. A partir do tempo e da experiência, as expectativas de sucesso se atualizam e indicadores subjetivos, como a satisfação no trabalho e a busca da realização pessoal e profissional, são priorizados (Oliveira et al., 2013).

Diante do exposto, constata-se que o sucesso na transição universidade-trabalho é um fenômeno multidimensional que pode ser avaliado por meio de um conjunto diversificado de indicadores típicos dos anos iniciais da carreira. Nessa linha de compreensão, Oliveira, Melo-Silva, Taveira e Postigo (2019), em estudo com recém-formados, identificaram que o sucesso nesta fase da carreira envolve confiança no futuro, planejamento de carreira, construção da identidade profissional, congruência trabalho-formação, independência financeira, adaptação ao trabalho, satisfação com a trajetória de carreira e reconhecimento profissional.

Numa outra perspectiva, considerando a Teoria da Psicologia do Trabalhar (Psychology of Working Theory), Masdonati et al. (2021) postularam um modelo explicativo do sucesso na transição para o trabalho dando destaque para os fatores contextuais, associados à classe socioeconômica, às origens familiares e ao gênero como preditores diretos ou indiretos dos resultados alcançados. Para os autores, as desvantagens do contexto social ou derivadas da marginalização dificultam a qualidade da inserção no mercado de trabalho. Por outro lado, recursos psicossociais, como a adaptabilidade de carreira e a autoeficácia, e processos de construção identitária são considerados mediadores da relação entre os aspectos contextuais e o sucesso na transição. O modelo destaca ainda o papel moderador exercido pelas características dos sistemas educacionais, das condições do mercado de trabalho, do suporte social e da consciência crítica. Enfatiza que os estudantes e recém-formados, para serem considerados bem-sucedidos nesta transição, precisam ser capazes de encontrar um trabalho compatível com o nível educacional e de manter a empregabilidade. Por fim, como indicadores de resultado a médio e longo prazo, espera-se que os recém-formados consigam conquistar um trabalho decente, significativo e com propósito.

Dessa forma, a literatura científica indica que recursos psicossociais podem ser considerados preditores diretos ou indiretos do sucesso na carreira. Por isso, é possível afirmar que a conquista de bons resultados na transição para o trabalho depende, em parte, do engajamento com a carreira. Segundo Hirschi, Freund e Herrmann (2014, p. 577), “o engajamento com a carreira pode ser definido como o grau em que alguém manifesta comportamentos proativos de carreira, com o objetivo de desenvolvê-la". Comportamentos relacionados ao engajamento com a carreira envolvem, entre outros aspectos, o planejamento de carreira, a construção da rede de contatos e a exploração de carreira.

Por suas características, para entender os determinantes do sucesso na transição universidade-trabalho, os especialistas recomendam a adoção de uma perspectiva que considere tanto os fatores contextuais quanto os recursos psicossociais, pois, no atual contexto socioeconômico, a inserção profissional e a conquista de bons resultados na carreira não dependem apenas do engajamento dos indivíduos com a carreira. Portanto, para ter sucesso nesta transição e na construção da carreira de uma maneira geral, é necessário aprender a decodificar continuamente a realidade social, encontrar suporte e engajar-se nas 
tarefas de carreira, simultaneamente. E, ao mesmo tempo, não perder de vista que políticas públicas para a geração de trabalho e renda são necessárias.

Tendo em vista a relevância do engajamento com a carreira para a compreensão do sucesso na carreira, pesquisadores têm se dedicado a estudar a relação entre essas variáveis no contexto da transição universidade-trabalho. Upadyaya e Salmela-Aro (2015) acompanharam jovens adultos, desde os últimos anos do ensino médio até a transição para o ensino superior ou para o trabalho, com o objetivo de analisar as relações entre o engajamento e a satisfação com a carreira ao longo do tempo. Os resultados mostraram dois tipos de perfis entre os participantes. O perfil com mais recursos para lidar com a transição apresentou nível inicial elevado de satisfação na carreira, que diminuiu ligeiramente durante a transição para o ensino superior/trabalho, e um nível elevado de engajamento com a carreira, que aumentou durante a transição. Houve também um segundo perfil, que iniciou com um baixo nível de satisfação e de engajamento com a carreira, porém, durante a transição para o ensino superior/trabalho, aumentaram ambos os indicadores. Em ambos os grupos, após a transição, o nível de engajamento permaneceu superior ao nível de satisfação na carreira.

Acrescenta-se, também, o estudo de Nilforooshan e Salimi (2016) que analisou a relação entre dimensões da personalidade e engajamento com a carreira, enfatizando o papel mediador da adaptabilidade de carreira, que consiste em recursos psicológicos para lidar com transições de carreira. Os resultados demonstraram que a dimensão da personalidade, associada à ação e à energia para o trabalho, relacionou-se significativamente com o engajamento com a carreira quando mediadas pela adaptabilidade de carreira. Na direção contrária, o estudo mostrou que os estudantes com traços de neuroticismo, que apresentam maiores indicadores de ansiedade, depressão, dependência e baixa autoestima, demonstraram maior dificuldade em se engajar em atividades da carreira.

O estudo de Assumpção e Oliveira (2018) apontou que aqueles estudantes que durante a graduação se envolveram mais em atividades extracurriculares apresentaram maiores níveis de engajamento com a carreira, já que essas atividades proporcionam oportunidades de aprendizado e desenvolvimento de carreira. As autoras concluem que é importante que as instituições de ensino superior estimulem seus estudantes oferecendo estrutura e recursos, a fim de viabilizar experiências e atividades que estimulem o desenvolvimento de comportamentos proativos de carreira tendo em vista que o engajamento com a carreira é um bom preditor de bons resultados na transição para o trabalho.

Em síntese, constata-se o crescente interesse pelo estudo do engajamento com a carreira no contexto da transição para o trabalho, pois as evidências sugerem que estar envolvido com o processo de desenvolvimento de carreira é essencial para que os estudantes consigam se preparar para a vida profissional e para gerir suas carreiras de forma crítica e sustentável. Além disso, o engajamento com a carreira está relacionado com outras formas de engajamento, tais como o engajamento com os estudos, com o trabalho e com as transições de carreira (Baluku et al., 2021).

Partindo desse quadro de referência, questões de pesquisa foram formuladas e buscaram explicar como o engajamento com a carreira impacta nos indicadores de sucesso na transição e como varia ao longo do tempo, durante e após a conclusão da graduação. Como hipóteses, espera-se que o engajamento com a carreira varie em função do tempo e seja maior após a conclusão da graduação. Além disso, tem-se como expectativa que o engajamento com a carreira, medido durante a após a conclusão da graduação, seja um preditor significativo, responsável pelas variações nos indicadores do sucesso na transição da universidade para o mercado de trabalho. Com o intuito de contribuir com a ampliação das investigações sobre o sucesso na carreira na perspectiva dos egressos do ensino superior, esta investigação objetivou, por meio de um estudo prospectivo com medidas repetidas, analisar as variações do engajamento com a carreira, durante e após a conclusão da graduação, além de verificar seu poder preditivo sobre o sucesso na transição universidade-trabalho.

\section{Método}

Trata-se de um estudo com delineamento prospectivo, de natureza quantitativa e com finalidade explicativa. A pesquisa prospectiva é recomendada quando se quer estudar um processo ao longo do tempo. Assim, para responder aos problemas de pesquisa e melhor analisar o fenômeno investigado, optou-se por coletar as informações com os mesmos participantes em dois momentos diferentes da transição universidade-trabalho: durante o último ano acadêmico e após a conclusão da graduação. 


\section{Participantes}

Tendo em vista o delineamento prospectivo com medidas repetidas, os mesmos participantes foram investigados em dois momentos diferentes: Tempo 1, durante a graduação, e Tempo 2, após a conclusão. Para composição da amostra algumas especificidades foram consideradas para a seleção dos participantes: a) selecionar, no Tempo 1, universitários de diferentes áreas de formação, que estivessem no último ano da graduação, com perspectiva de graduar-se em até 12 meses; e b) acessar esses mesmos participantes para a coleta de dados no Tempo 2, após a graduação.

Participaram do Tempo 1 da coleta de dados, realizada entre o segundo semestre de 2016 e o primeiro de 2018, 472 estudantes universitários de diversos cursos que estavam matriculados no último ano da graduação. Os participantes foram majoritariamente mulheres $(\mathrm{N}=299 ; 63,3 \%)$, da cor branca $(\mathrm{N}=345$; $71,3 \%)$ e estudantes de universidades públicas $(\mathrm{N}=255$; $54 \%)$. As idades variaram de 18 a 56 anos $(M=24.52$; $D P=5,15)$. Participaram do Tempo 2 da pesquisa, realizada no primeiro semestre de 2019, 108 recém-formados que responderam aos questionários nos dois momentos da coleta de dados. No Tempo 2, os participantes foram majoritariamente mulheres $(\mathrm{N}=80$; $74,1 \%)$, da cor branca $(\mathrm{N}=88 ; 81,5 \%)$ e graduados em universidades públicas ( $\mathrm{N}=94 ; 87 \%)$. Em relação à idade, os participantes tinham entre 21 e 52 anos, e a média foi de 25.68 ( $\mathrm{DP}=4,03)$. O tempo decorrido da conclusão da graduação variou de 1 a 28 meses, sendo que a média foi de 13,76 meses (DP=7,14). Em relação à graduação concluída, os 108 participantes estavam distribuídos em 27 cursos, sendo agrupados em seis grandes áreas do conhecimento: Ciências Humanas (N=57; 52,8\%), Ciências da Saúde (N=26; 24,1\%), Engenharias $(\mathrm{N}=8 ; 7,4 \%)$, Ciências Sociais $(\mathrm{N}=7$; 6,5\%), Outros ( $\mathrm{N}=7 ; 6,5 \%)$ e Ciências Exatas e da Terra (N=3; 2,8\%). Quanto ao curso de formação, a maioria se graduou em Psicologia ( $N=55 ; 50,9 \%$ ), seguido por Biomedicina ( $\mathrm{N}=7 ; 6,5 \%)$ e Fisioterapia ( $\mathrm{N}=5 ; 4.6 \%)$.

\section{Instrumentos}

Escala de Engajamento com a Carreira (Hirschi et al., 2014; Marques, Oliveira, \& MeloSilva, 2019). Trata-se de uma medida unidimensional, composta por nove itens, que objetiva avaliar, de modo geral, o quanto as pessoas manifestaram, nos últimos seis meses, comportamentos proativos de carreira associados ao planejamento de carreira (exemplo: "construiu planos e definiu objetivos para sua carreira"), conhecimento de si em relação à carreira (exemplo: "refletiu, sinceramente, sobre seus valores pessoais, suas habilidades e suas fraquezas"), conhecimento do ambiente de carreira (exemplo: "coletou informações sobre empregadores, oportunidades de desenvolvimento profissional ou mercado de trabalho em sua área de interesse"), rede de contatos (exemplo: "estabeleceu contato com pessoas que poderiam colaborar na construção da sua carreira"), investimento voluntário no capital humano/desenvolvimento de habilidades e o desenvolvimento de habilidades de recolocação (exemplo: "participou, voluntariamente, em ações educativas, treinamentos ou outros eventos que apoiassem na construção da sua carreira"). A versão brasileira da escala tem boa confiabilidade, apresentando um alfa de Cronbach de .80 (Marques et al., 2019).

Escala de Avaliação do Sucesso na Transição Universidade-Trabalho (Oliveira, Melo-Silva, Taveira \& Grace, 2016). Trata-se de uma medida composta por 22 itens que avaliam quatro dimensões do sucesso na transição universidade-trabalho, sendo eles: inserção e satisfação profissional (exemplos: "consegui um trabalho na minha área de formação"; "estou atuando profissionalmente naquilo que planejei”), confiança no futuro de carreira (exemplos: "estou confiante em relação ao meu futuro profissional"; "tenho boas expectativas em relação ao meu futuro profissional"), remuneração e independência financeira (exemplos: "consigo pagar as minhas contas"; "tenho condições de comprar as coisas que me interessam") e a adaptação ao trabalho (exemplos: "estou adaptado às exigências do mundo do trabalho"; "estou adaptado à cultura do mundo do trabalho"). A escala tem boa confiabilidade geral e das subescalas, apresentando um alfa de Cronbach de .92.

\section{Procedimentos éticos, de coleta e análise de dados}

Esta pesquisa foi aprovada pelo Comitê deÉtica em Pesquisa da Universidade dos primeiros autores, sob o parecer $\mathrm{n}^{\circ}$ 1.376.349 e CAAE 50824115.7.0000.5154. A investigação seguiu as normas do Ministério da Saúde e do Conselho Federal de Psicologia. No Tempo 1 da pesquisa, os participantes foram convidados a colaborar com a pesquisa e, para aqueles que decidiram participar voluntariamente, foram explicitados os 
objetivos, os instrumentos, seu caráter longitudinal e o tempo de duração para responder ao caderno de pesquisa. Antes de iniciarem o preenchimento do caderno de pesquisa, foi solicitado que lessem e assinassem o Termo de Consentimento Livre e Esclarecido. Nessa etapa da pesquisa, a coleta de dados aconteceu presencialmente e on-line. No Tempo 2, os mesmos procedimentos éticos foram seguidos, mas a coleta de dados ocorreu apenas pela plataforma on-line.

A análise dos dados foi feita a partir do software IBM SPSS (Statistical Package for the Social Sciences) versão 23. Para o estudo descritivo e correlacional foram utilizadas estatísticas descritivas, testes de correlação ( $r$ de Pearson), teste de comparação entre grupos (ANOVA) com amostras pareadas. Além disso, foi calculado o $d$ de Cohen para conhecer o tamanho do efeito das diferenças. Para o estudo preditivo foram realizadas análises de regressão linear múltipla. Antes de serem iniciadas as análises estatísticas, os pressupostos teóricos para sua realização foram testados, sendo atendidos os requisitos de pelo menos 20 participantes por variável independente, resíduos independentes, ausência de multicolinearidade e de outliers, resíduos normalmente distribuídos e homocedasticidade.

Para ambas as escalas, o formato de respostas é do tipo Likert, que varia de 1 (não muito/discordo totalmente) a 5 (sempre/concordo totalmente). Valores próximos de 1 indicam baixo engajamento com a carreira ou baixa percepção de sucesso nos indicadores avaliados.

\section{Resultados e discussão}

Com o intuito de testar as hipóteses iniciais, o estudo subdividiu-se em dois momentos. Primeiramente, buscou-se analisar as variações do engajamento com a carreira, durante e após a conclusão da graduação. Em seguida, verificou-se o poder preditivo do engajamento com a carreira sobre o sucesso na transição universidade-trabalho, controlando a variável tempo de conclusão da graduação.

\section{Estudo descritivo e correlacional}

Na Tabela 1 são apresentados os valores máximos e mínimos, média, desvio-padrão e os valores das assimetrias e curtoses de cada uma das variáveis do estudo.

Tabela 1

Valores de mínimo e máximo, média, desvio-padrão e assimetria curtose (N=108).

\begin{tabular}{|c|c|c|c|c|c|c|}
\hline & Mínimo & Máximo & M & $\mathrm{DP}$ & $\begin{array}{c}\text { Assimetria } \\
\text { (Erro Padrão }=.23 \text { ) }\end{array}$ & $\begin{array}{c}\text { Curtose } \\
\text { (Erro Padrão =.46) }\end{array}$ \\
\hline $\begin{array}{c}\text { Engajamento com a Carreira Durante } \\
\text { a Graduação }\end{array}$ & 1.67 & 5.00 & 3.82 & .62 & -.35 & .46 \\
\hline $\begin{array}{l}\text { Engajamento com a Carreira Depois } \\
\text { da Graduação }\end{array}$ & 2.22 & 5.00 & 4.01 & .63 & -.63 & .01 \\
\hline Inserção e Satisfação Profissional & 1.00 & 5.00 & 3.72 & 1.27 & -.83 & -.59 \\
\hline $\begin{array}{l}\text { Remuneração e Independência } \\
\text { Financeira }\end{array}$ & 1.00 & 5.00 & 2.88 & 1.18 & -.01 & -1.18 \\
\hline Adaptação ao Trabalho & 1.20 & 5.00 & 3.71 & .92 & -.72 & .06 \\
\hline Confiança no Futuro de Carreira & 1.00 & 5.00 & 3.83 & .92 & -.81 & .29 \\
\hline $\begin{array}{c}\text { Tempo de Conclusão da Graduação } \\
\text { (meses) }\end{array}$ & 1.00 & 28.00 & 13.76 & 7.14 & .35 & -1.10 \\
\hline
\end{tabular}

Como pode ser observado na Tabela 1, a média do engajamento com a carreira após a conclusão da graduação foi maior que a média obtida pelos participantes durante a graduação. Para esses resultados a diferença foi estatisticamente significativa $[\mathrm{t}(\mathrm{gl}=107 .=\mathrm{t}=-2,84, \mathrm{p}>0,05)$. Adicionalmente, $\mathrm{o}$ indicador $d$ de Cohen mostrou que o efeito da diferença entre as médias durante e após a graduação, embora significativa, foi de intensidade pequena $(\mathrm{d}=-.30)$.
De modo geral, os resultados mostraram que os estudantes, durante o último ano da graduação, obtiveram um nível médio, tendendo ao bom, no engajamento com a carreira, uma vez que a média esteve ligeiramente acima do ponto médio da escala. Já após a conclusão da graduação, o engajamento com a carreira aumentou, estando acima do ponto médio.

Esses resultados reforçam a ideia de que o engajamento com a carreira sofre variações ao longo do 
tempo enfatizando seu aspecto contextual e comportamental. A variabilidade do construto ao longo do tempo também foi identificada em outros estudos que mostraram que o engajamento com a carreira de trabalhadores já inseridos no mercado de trabalho tende a ser maior do que de estudantes (Hirschi \& Freund, 2014; Hirschi et al., 2014). Pensando numa perspectiva processual, no último ano da graduação a maioria dos estudantes universitários investem a maior parte do tempo em atividades de desenvolvimento de carreira, tais como experiências de estágio e de extensão, buscando explorar seus interesses e habilidades para então decidir a futura carreira e as oportunidades de trabalho que lhe interessam (Kim et al., 2014). Após a conclusão dos estudos, os comportamentos proativos de carreira tendem a se intensificar (Upadyaya \& Salmela-Aro, 2015), na medida que se direcionam para as atividades de inserção profissional, que demandam um alto grau de engajamento com a construção da carreira. Nesse sentido, os resultados corroboram a ideia de que para reduzir o tempo de transição e o estresse associado aos períodos de desemprego ou de flutuações entre trabalhos típicos desta fase da carreira, é recomendável que os estudantes se mantenham engajados para vivenciar o processo de transição durante e após da conclusão dos estudos (Baluku et al., 2021; Vieira et al., 2011).

Para os indicadores de sucesso na transição universidade-trabalho, os resultados relativos a esta amostra de recém-formados mostraram que em relação a inserção e satisfação profissional, adaptação ao trabalho e confiança no futuro de carreira, os participantes obtiveram um nível médio, tendendo a bom, uma vez que as médias se encontraram ligeiramente acima do ponto médio da escala. Por outro lado, no indicador remuneração e independência financeira, a média situou-se abaixo do ponto médio, indicando que nesta dimensão os recém-formados não estão tão bem quanto nos demais indicadores de sucesso na transição. Esses resultados mostram as dificuldades enfrentadas por recém-graduados em início de carreira para conquistar remuneração adequada compatível com a formação de nível superior (Reis \& Diehl, 2017). A falta de experiência e a alta competitividade do mercado de trabalho dificultam a obtenção de uma boa remuneração capaz de viabilizar a independência financeira logo após a graduação. Por isso, é importante que os recém-formados consigam contextualizar suas dificuldades para obtenção de boa remuneração nos anos iniciais da carreira e não considerem essa situação como um indicador de fracasso na carreira (Oliveira et al., 2019).

Em continuidade à apresentação dos resultados, a Tabela 2 sintetiza os resultados das correlações entre as variáveis, algumas das quais merecem destaque. Observou-se que o engajamento com a carreira medido durante a graduação apresentou correlações significativas somente com o engajamento com a carreira depois da graduação e com os indicadores de sucesso relacionados à adaptação ao trabalho e à confiança no futuro de carreira. Já o engajamento com a carreira depois da graduação, além das correlações significativas com o engajamento com a carreira durante a graduação, apresentou correlações significativas com todos os indicadores de sucesso na transição universidade-trabalho analisados. A menor correlação foi com o indicador remuneração e independência financeira. O tempo decorrido da conclusão da graduação não apresentou correlações significativas com o engajamento com a carreira durante e após a conclusão da graduação.

\section{Tabela 2}

Correlações entre as variáveis em estudo $(\mathrm{N}=108)$.

\begin{tabular}{lcccccccc}
\hline & & $\mathbf{1}$ & $\mathbf{2}$ & $\mathbf{3}$ & $\mathbf{4}$ & $\mathbf{5}$ & $\mathbf{6}$ & $\mathbf{7}$ \\
\hline $\mathbf{1}$ & Tempo de Conclusão da Graduação & 1 & & & & & & \\
$\mathbf{2}$ & Engajamento com a Carreira Durante a Graduação & -.12 & 1 & & & & & \\
$\mathbf{3}$ & Engajamento com a Carreira Depois da Graduação & -.03 & $.36^{* *}$ & 1 & & & & \\
$\mathbf{4}$ & Inserção e Satisfação Profissional & $.20^{*}$ & $.04^{* *}$ & $.40^{* *}$ & 1 & & & \\
$\mathbf{5}$ & Remuneração e Independência Financeira & $.27^{* *}$ & .09 & $.21^{*}$ & $.62^{* *}$ & 1 & & \\
$\mathbf{6}$ & Adaptação ao Trabalho & .16 & $.24^{*}$ & $.49^{* *}$ & $.70^{* *}$ & $.65^{* *}$ & 1 & \\
$\mathbf{7}$ & Confiança no Futuro de Carreira & .11 & $.22^{*}$ & $.50^{* *}$ & $.58^{* *}$ & $.51^{* *}$ & $.66^{* *}$ & 1 \\
\hline
\end{tabular}

${ }^{*} \mathrm{p}<.05 ;{ }^{* *} \mathrm{p}<.01$. 
A partir dos resultados constatou-se que o engajamento com a carreira, medido prospectivamente, se relacionou de modo mais significativo com os indicadores de sucesso na transição universidade-trabalho, do que quando aferido inicialmente na graduação. Manifestar comportamentos proativos de carreira durante a graduação se mostrou relacionado com o engajamento com a carreira após a conclusão dos estudos que, por sua vez, relacionou-se positivamente com confiança no futuro de carreira, inserção e satisfação profissional e adaptação ao trabalho. Nessa mesma direção, Masdonati et al. (2021) reconhecem que para conquistar o sucesso na transição universidade-trabalho, os recém-formados precisam, entre outros aspectos, manter-se engajados e identificados com a carreira, assim como confiantes em suas capacidades para se inserir profissionalmente.

Por outro lado, o tempo de conclusão da graduação não se relacionou significativamente com o engajamento com a carreira. Inclusive, os resultados foram negativos e sinalizaram que quanto maior o tempo decorrido da conclusão dos estudos, menor tende a ser o engajamento com a carreira. Ademais, os indicadores de inserção e satisfação profissional, remuneração e independência financeira mostraram relações com o tempo de conclusão. Esses resultados dialogam com reflexões de Baluku et al. (2021) sobre a qualidade da transição para o trabalho em função do tempo para conseguir a primeira oportunidade profissional estável e satisfatória após a conclusão dos estudos. Desse modo, para lidar com os desafios da inserção profissional dos egressos do ensino superior, além de incentivar o engajamento com a carreira, é preciso também investir urgentemente em políticas públicas para abertura de novas vagas de trabalho compatíveis com a formação de nível superior que viabilizem o desenvolvimento individual e social de forma sustentável (Oliveira, Melo-Silva, \& Taveira, 2021).

\section{Estudo preditivo}

Em um primeiro momento testou-se o efeito preditivo do engajamento com a carreira durante a graduação sobre o engajamento com a carreira depois da conclusão da graduação. As análises mostraram que quando manifestado durante a graduação, foi capaz de explicar $12 \%$ a variância do constructo após a graduação. Apesar do tamanho de efeito dessa relação se mostrar pequeno, resultou em um modelo estatisticamente significativo [ $\left.\mathrm{F}(\mathrm{gl}=107, \mathrm{~N}=108) ; \mathrm{p}>0,05 ; \mathrm{R}^{2}=.129\right]$.

Na sequência, novas regressões lineares múltiplas foram realizadas para verificar o poder preditivo do engajamento com a carreira, durante e após a conclusão dagraduação, nos indicadores do sucessona transição universidade-mercado de trabalho, medidos após a conclusão da graduação. Nestas análises, controlouse o tempo de conclusão da graduação, por se entender que essa variável se relaciona com a conquista dos resultados na carreira. Para isso foram esquematizados três modelos, que são descritos na Tabela 3.

Tabela 3

Regressões hierárquicas para as dimensões do sucesso na transição universidade-trabalho (N=108).

\begin{tabular}{|c|c|c|c|c|c|c|c|c|c|c|c|c|}
\hline & \multicolumn{3}{|c|}{$\begin{array}{l}\text { Inserção e Satisfação } \\
\text { Profissional }\end{array}$} & \multicolumn{3}{|c|}{$\begin{array}{l}\text { Remuneração e } \\
\text { Independência } \\
\text { Financeira }\end{array}$} & \multicolumn{3}{|c|}{$\begin{array}{c}\text { Adaptação ao } \\
\text { Trabalho }\end{array}$} & \multicolumn{3}{|c|}{$\begin{array}{c}\text { Confiança Futura de } \\
\text { Carreira }\end{array}$} \\
\hline & $\mathrm{R}^{2}$ & $\Delta \mathrm{R}^{2}$ & $\beta$ & $\mathrm{R}^{2}$ & $\Delta \mathrm{R}^{2}$ & $\beta$ & $\mathrm{R}^{2}$ & $\Delta \mathrm{R}^{2}$ & $\beta$ & $\mathrm{R}^{2}$ & $\Delta \mathrm{R}^{2}$ & $\beta$ \\
\hline Bloco I & .002 & -.007 & & .009 & .000 & & $.060^{*}$ & $.052^{*}$ & & $.052^{*}$ & $.043^{*}$ & \\
\hline $\begin{array}{l}\text { Engajamento com } \\
\text { a Carreira durante } \\
\text { a graduação }\end{array}$ & & & .045 & & & .094 & & & $.246^{*}$ & & & $.228^{*}$ \\
\hline Bloco II & $.175^{* *}$ & $.160^{* *}$ & & $.047^{*}$ & $.028^{*}$ & & $.247^{* *}$ & $.233^{* *}$ & & $.253^{* *}$ & $.239^{* *}$ & \\
\hline $\begin{array}{l}\text { Engajamento com } \\
\text { a Carreira durante } \\
\text { a graduação }\end{array}$ & & & -.116 & & & .019 & & & .079 & & & .055 \\
\hline $\begin{array}{l}\text { Engajamento com } \\
\text { a Carreira após } \\
\text { a conclusão da } \\
\text { graduação }\end{array}$ & & & $.446^{* *}$ & & & $.208^{*}$ & & & $.463^{* *}$ & & & $.480^{* *}$ \\
\hline
\end{tabular}

continua... 


\begin{tabular}{|c|c|c|c|c|c|c|c|c|c|c|c|c|}
\hline & \multicolumn{3}{|c|}{$\begin{array}{l}\text { Inserção e Satisfação } \\
\text { Profissional }\end{array}$} & \multicolumn{3}{|c|}{$\begin{array}{l}\text { Remuneração e } \\
\text { Independência } \\
\text { Financeira }\end{array}$} & \multicolumn{3}{|c|}{$\begin{array}{l}\text { Adaptação ao } \\
\text { Trabalho }\end{array}$} & \multicolumn{3}{|c|}{$\begin{array}{c}\text { Confiança Futura de } \\
\text { Carreira }\end{array}$} \\
\hline & $\mathrm{R}^{2}$ & $\Delta \mathrm{R}^{2}$ & $\beta$ & $\mathrm{R}^{2}$ & $\Delta \mathrm{R}^{2}$ & $\beta$ & $\mathrm{R}^{2}$ & $\Delta \mathrm{R}^{2}$ & $\beta$ & $\mathrm{R}^{2}$ & $\Delta \mathrm{R}^{2}$ & $\beta$ \\
\hline Bloco III & $.215^{*}$ & $.193^{*}$ & & $.131^{*}$ & $.106^{*}$ & & $.284^{*}$ & $.263^{*}$ & & .271 & .250 & \\
\hline $\begin{array}{c}\text { Engajamento com } \\
\text { a Carreira durante } \\
\text { a graduação }\end{array}$ & & & -.089 & & & .059 & & & .105 & & & .073 \\
\hline $\begin{array}{l}\text { Engajamento com a } \\
\text { Carreira no Tempo } 2 \\
\text { após a conclusão da } \\
\text { graduação }\end{array}$ & & & $.443^{* *}$ & & & $.203^{*}$ & & & $.460^{* *}$ & & & $.478^{* *}$ \\
\hline $\begin{array}{l}\text { Tempo de } \\
\text { Conclusão da } \\
\text { Graduação }\end{array}$ & & & $.202^{*}$ & & & $.292^{*}$ & & & $.193^{*}$ & & & .137 \\
\hline
\end{tabular}

Em relação à dimensão inserção e satisfação profissional, o bloco III, com as variáveis independentes engajamento com a carreira, durante e após a graduação, e tempo de conclusão da graduação, foi o que apresentou os melhores indicadores, capazes de explicar $19 \%$ da variação desse indicador do sucesso. Nesse modelo, somente o engajamento com a carreira após a graduação $(\beta=.443 ; \mathrm{t}=4.75 ; \mathrm{p}<0.01)$ e o tempo de conclusão de curso $(\beta=.202 ; \mathrm{t}=2.30$; $\mathrm{p}<0.5)$ mostraram-se preditores significativos da inserção e satisfação profissional, sendo que o engajamento com a carreira depois da graduação apresentou melhor poder preditivo.

Nesse sentido, os resultados indicam que aqueles indivíduos que continuam exibindo comportamentos proativos de carreira após a conclusão da graduação, com a intenção de melhorar seu desenvolvimento profissional, tendem a conseguir um trabalho ou se vincular à sua área de formação, além de se sentirem mais identificados com o papel de trabalhador e com sua profissão. Contudo, os resultados também sinalizam que para que isso ocorra, o tempo de conclusão da graduação também deve ser considerado. Com efeito, evidências científicas têm demonstrado que transitar da universidade para o mercado de trabalho, longe de ser uma transição trivial e automática, é uma tarefa de desenvolvimento particularmente desafiadora, principalmente para os mais jovens em início de carreira (Masdonati et al., 2021). Nesse sentido, os resultados corroboram o aspecto processual da transição universidade-trabalho e sinalizam que os universitários precisam estar engajados para vivenciar o processo antes da conclusão dos estudos e da inserção profissional. Manter-se engajado com a carreira, durante e após a graduação, pode ajudar a reduzir o tempo para conseguir trabalho e reduzir o estresse associado aos períodos de desemprego ou de flutuações entre trabalhos, típicos desta fase da carreira (Baluku et al., 2021).

Quanto à dimensão remuneração e independência financeira, de forma semelhante aos resultados da inserção e satisfação profissional, o bloco III foi o que apresentou os melhores indicadores capazes de explicar aproximadamente $10 \%$ da variação desse indicador do sucesso na transição para o trabalho. Somente o engajamento com a carreira após a graduação $(\beta=.203 ; t=2.07 ; p<0.01)$ e o tempo de conclusão da graduação $(\beta=.292 ; \mathrm{t}=3.17$; $\mathrm{p}<0.01)$ foram preditores significativos da remuneração e de independência financeira, sendo o tempo decorrido da conclusão dos estudos a variável que apresentou melhor poder preditivo. Esses resultados sugerem que aqueles recém-formados que após a conclusão da graduação continuaram planejando seu futuro profissional, estabelecendo metas, dialogando com suarede de contatos e assumindo responsabilidades e funções para ajudá-los a progredir na carreira, foram os que conseguiram melhores resultados relacionados à remuneração e à independência financeira. Frente as evidências obtidas é importante considerar que receber uma remuneração adequada e compatível com as qualificações, experiências e esforços individuais é um dos indicadores de trabalho decente (Masdonati et al., 2021). 
Contudo, as projeções do mercado de trabalho para trabalhadores em início de carreira sinalizam impactos que podem afetar uma geração inteira (OIT, 2020). Por isso, é importante que os recémformados consigam contextualizar suas dificuldades, caso não consigam logo após a conclusão da graduação encontrar trabalho satisfatório, com boa remuneração e compatível com a formação de nível superior (Masdonati et al., 2021).

Nessa mesma direção, Oliveira et al. (2019) argumentam que a conquista de remuneração e independência financeira após a conclusão da graduação, não ocorre de forma semelhante para todos os recém-formados e, por isso, deve ser analisada de forma contextual. Caso contrário, os recém-formados podem facilmente frustrar suas expectativas e sentirem-se fracassados na transição para o trabalho. Ainda, é importante problematizar que no contexto contemporâneo a conquista de boa remuneração e de independência financeira tem ocorrido de forma lenta para os jovens recém-formados. Ademais, a crise sanitária e econômica impactou fortemente o mercado de trabalho, sobretudo para as juventudes. Por isso, entender a dinâmica do mercado de trabalho para as ocupações de nível superior e engajar-se nas lutas sociais por melhores condições de trabalho e de remuneração são tão importantes quanto se manter engajado com a própria carreira.

De forma parecida aos resultados anteriores, no indicador adaptação ao trabalho o bloco III também foi o que apresentou os melhores indicadores capazes de explicar $26 \%$ da variação da adaptação ao trabalho. Nesse modelo, o engajamento com a carreira após a graduação $(\beta=.460 ; \mathrm{t}=5.16 ; \mathrm{p}<0.01)$ e o tempo de conclusão de curso $(\beta=.193 ; \mathrm{t}=2.30$; $\mathrm{p}<0.5$ ) foram preditores significativos da adaptação ao trabalho, sendo que o engajamento com a carreira depois da graduação apresentou melhor poder preditivo. Os resultados indicaram que aqueles recémformados que se mostraram engajados em sua carreira apresentando comportamentos proativos tendem a se adaptar melhor ao trabalho, assumindo responsabilidades por seu próprio desempenho, apresentando uma boa atuação e adaptando-se com mais facilidade à cultura organizacional e ao mundo do trabalho. Entretanto, os resultados sinalizam que para que isso ocorra o tempo de conclusão da graduação também deve ser considerado.
De fato, a literatura tem reforçado que a inserção profissional é para muitos recém-formados a primeira grande tarefa de adaptação ao trabalho com impactos significativos no desenvolvimento de carreira subsequente (Baluku et al., 2021). Portanto, os resultados convergem reforçando o aspecto processual da transição universidade-trabalho. Ademais, para que o sucesso aconteça no menor tempo possível é necessário reconhecer a existência de marcadores sociais das desigualdades e trabalhar de forma articulada para sua superação (Masdonati et al., 2021).

Já em relação à dimensão confiança no futuro de carreira, o bloco II apresentou os melhores indicadores capazes de explicar $23 \%$ da variação desse indicador do sucesso. Observou-se nesse modelo que o engajamento com carreira tanto durante a graduação $(\beta=.055 ; \mathrm{t}=0,60 ; \mathrm{p}<0,01)$ quanto após a graduação $(\beta=.480 ; t=5,31 ; p<0,01)$ foram preditores significativos da confiança no futuro de carreira, sendo que o engajamento com a carreira depois da graduação apresentou melhor poder preditivo. Esses resultados sinalizaram que refletir sobre interesses e habilidades, planejar o futuro profissional, traçar objetivos de carreira, estabelecer uma rede de contatos são comportamentos que devem ocorrer durante e após a conclusão da graduação para que o recém-formado consiga manter a confiança no futuro de sua carreira. Diferente dos indicadores de sucesso anteriormente descritos, a confiança no futuro de carreira não se mostrou diretamente impactada pelo tempo de conclusão da graduação. Os resultados evidenciaram que o engajamento com a carreira, se manifestado de forma contínua durante a após a conclusão dos estudos, tem potencial para ajudar o recém-formado a demonstrar maior controle emocional na gestão das inseguranças e dos medos diante do futuro profissional, além proporcionar maior confiança na capacidade de se inserir no mercado. Da mesma forma, vários estudos também relataram a relação entre engajamento com a carreira, sucesso na transição universidade-trabalho e autoeficácia de carreira (Baluku et al., 2021; Hirschi, et al., 2014; Kim et al., 2014; Masdonati et al., 2021). Assim, estar engajado com a carreira, durante e após a graduação, mostrou-se ser um bom preditor da confiança nas próprias capacidades e no futuro de carreira. 


\section{Considerações finais}

A transição para o trabalho constitui-se como uma tarefa de grande importância para o desenvolvimento de carreira. As rápidas mudanças na estrutura econômica e tecnológica em curso na sociedade, somadas ao aumento das pessoas com ensino superior e da escassez de oportunidades no mercado de trabalho, têm exigido diferentes perspectivas para explicar o sucesso nos anos iniciais da carreira. Um dos elementos identificados pela literatura capaz de ajudar os indivíduos a enfrentaram os momentos de transição é o engajamento com a carreira, que consiste em comportamentos proativos que favorecem o desenvolvimento e a construção da carreira.

Partindo de um delineamento prospectivo, as conclusões deste estudo acrescentam à literatura contribuições teóricas, práticas e sugestões para futuras pesquisas. Em relação às contribuições teóricas, os resultados ampliam a compreensão da relação entre o engajamento com a carreira e o sucesso na transição universidade-trabalho. De modo geral, os resultados corroboraram as expectativas teóricas acerca da importância dos comportamentos proativos de carreira, relacionados ao engajamento com a carreira, durante e, especialmente, após a conclusão da graduação. As evidências mostraram que estar engajado com a carreira durante a graduação, embora importante para explicar as variações do engajamento com a carreira depois da graduação, não foi suficiente para explicar as variações nos indicadores de sucesso na transição universidade-trabalho.

Deste modo, os resultados sinalizam novas perspectivas de análise da transiçãouniversidade-trabalho. Para conseguir explicar as variações nos indicadores de sucesso, o engajamento com a carreira precisa estar continuamente presente no comportamento dos universitários e recém-formados. Manter os comportamentos proativos direcionados à carreira após a conclusão da graduação parece ser mais significativo para explicar o sucesso na transição para o trabalho do que quando apresentados na graduação. Além disso, o tempo decorrido da conclusão de graduação mostrou-se uma variável preditora significativa que precisa ser considerada nos estudos sobre o sucesso nos anos iniciais da carreira.

Em suma, conquistar bons resultados nos anos iniciais da carreira pode ser explicado, em parte, pelo nível de engajamento com a carreira. Quando os estudantes universitários manifestam comportamentos proativos direcionados ao desenvolvimento de carreira durante a graduação e os intensificam após a conclusão dos estudos, as chances de obter sucesso na transição para o trabalho aumentam.

Embora o estudo não tenha se orientado por objetivos de natureza prática, algumas contribuições podem ser mencionadas nesse domínio. A primeira delas é que tanto as universidades quanto as organizações e o poder público podem contribuir com práticas inovadoras de educação e de gestão para fomentar a inserção e a adaptação dos recém-formados ao mercado de trabalho. Espera-se que as universidades invistam em iniciativas de educação para a carreira e no fortalecimento dos recursos psicológicos e das competências transversais de seus estudantes com vista a facilitar a inserção e a adaptação ao trabalho. Por sua vez, as organizações podem elaborar programas específicos para estimular o recrutamento e seleção de universitários e recém-formados, como também investir em programas de socialização organizacional para facilitar a adaptação inicial ao trabalho. Ademais, o poder público deve investir em parcerias com setores econômicos para a abertura de postos de trabalho compatíveis com a formação de nível superior (Oliveira et al., 2021).

Apesar das contribuições do estudo, algumas limitações podem ser consideradas, em especial aquelas relacionadas ao método. Devido ao delineamento prospectivo, que previu a coleta de dados em dois momentos distintos da trajetória de carreira dos participantes, houve uma perda considerável de participantes que não responderam ao questionário no segundo momento da coleta de dados. Essa limitação ocasionou um tamanho amostral próximo ao limite recomendado. Outra limitação relacionada à amostra refere-se ao perfil dos participantes, entre os quais predominam mulheres brancas e do curso de Psicologia. Assim, sugerem-se novas investigações com amostra ampliadas e diversificadas em função do sexo, da raça e das áreas do conhecimento. De certa forma, isso pode ter impactado nos indicadores estatísticos, inviabilizando as generalizações. Por outro lado, o delineamento prospectivo com os mesmos participantes em dois momentos diferentes permitiu explicar com maior precisão a relação entre o engajamento com a carreira e o sucesso na transição universidade-trabalho. 
Assim, futuras pesquisas podem ser pensadas a partir dos resultados aqui relatados. Para aumentar o poder explicativo do engajamento seria pertinente incluir nos modelos de regressão outras variáveis contextuais e psicológicas como antecedentes, mediadoras ou moderadoras do sucesso na transição universidade-trabalho (como em Masdonati et al., 2021). Por fim, espera-se que este estudo contribua com a literatura sobre a construção de carreira no contexto da transição para o trabalho, a fim de subsidiar novas pesquisas e intervenções direcionadas àqueles que vivenciam essa importante transição na carreira.

\section{Referências}

Assumpção, M. C., \& Oliveira, M. C. (2018). Estudo do engajamento com a carreira em universitários no processo de transição universidade-trabalho. Revista de Psicologia da UFC, 9(2), 153-162. http://www.periodicos.ufc.br/ psicologiaufc/article/view/20248

Baluku, M. M., Mugabi, E. N., Nansamba, J., Matagi, L., Onderi, P., \& Otto, K. (2021). Psychological capital and career outcomes among final year university students: The mediating role of career engagement and perceived employability. International Journal of Applied Positive Psychology, 6, 55-80. https:// doi.org/ 10.1007/s41042-020-00040-w

Hirschi, A., \& Freund, P. A. (2014). Career engagement: Investigating intraindividual predictors of weekly fluctuations in proactive career behaviors. Career Development Quarterly, 62(1), 5-20. https://doi. org/10.1002/j.2161-0045.2014.00066.x

Hirschi, A., Freund, P. A., \& Herrmann, A. (2014). The career engagement scale: Development and validation of a measure for proactive career behaviors. Journal of Career Assessment, 22(4), 575-594. https://doi. org/10.1177/1069072713514813

Instituto Nacional de Estudos e Pesquisas Educacionais Anísio Teixeira (2021). Resumo técnico do Censo da Educação Superior 2019 [recurso eletrônico]. https://download.inep.gov.br/publicacoes/institucionais/estatisticas_e_indicadores/resumo_tecnico_censo_da_educacao_superior_2019.pdf

Kim, B., Jang, S. H., Jung, S. H., Lee, B. H., Puig, A., \& Lee, S. M. (2014). A moderated mediation model of planned happenstance skills, career engagement, career decision self-efficacy, and career decision certainty. The Career Development Quarterly, 62(1), 56-69. https://doi.org/10.1002/j.2161-0045.2014.00070.x

Marques, B. C. S., Oliveira, M. C., \& Melo-Silva, L. L. (2019). Escala de engajamento com a carreira (EEC). In A. L. Andrade, M. F. O. Nunes, M. Z. Oliveira, \& R. A. M. Ambiel (Org.), Técnicas e medidas em orientação profissional e de carreira ( $1^{\text {a }}$ ed., pp. 49-60). Vetor.

Masdonati, J., Massoudi, K., Blustein, D. L., \& Duffy, R. D. (2021). Moving toward decent work: application of the Psychology of Working Theory to the school-to-work transition. Journal of Career Development, (n. spe.), 1-19. https://doi.org/10.1177/0894845321991681

Nilforooshan, P., \& Salimi, S. (2016). Career adaptability as a mediator between personality and career engagement. Journal of Vocational Behavior, 94(1), 1-10. https:// doi.org/10.1016/j.jvb.2016.02.010

Nora, N. C. (2017). Vidas congeladas - socializados para o trabalho, formados para o não emprego. In A. P. Marques, C. Sá, J. R. Casanova, L. S. Almeida (Orgs.), Ser diplomado do ensino superior: Escolhas, percursos e retornos. Centro de Investigação em Educação; Instituto de Educação da Universidade do Minho. http://repositorium. sdum.uminho.pt/handle/1822/47170

Oliveira, M. C., Detomini, V. C., \& Melo-Silva, L. L. (2013). Sucesso na transição universidade-trabalho: expectativas de universitários formandos. Psicologia em Revista, 19(3), 497-518. https://doi. org/10.5752/P.1678-9563.2013v19n3p497

Oliveira, M. C., Melo-Silva, L. L., \& Taveira, M. C. (2021). Orientação de carreira para universitários e recémgraduados na transição para o trabalho. In L. Oliveira \& E. Campos, Psicologia da carreira: Práticas em orientação, desenvolvimento e coaching de carreira (Vol. 2, pp. 101-118). Vetor.

Oliveira, M. C., Melo-Silva, L. L., Taveira, M. C., \& Grace, R. (2016). Measuring university-to-work success: Development of a new scale. Career Development International, 21(1), 85-104. https://doi.org/10.1108/ CDI-04-2015-0051

Oliveira, M. C., Melo-Silva, L. L., Taveira, M. C., \& Postigo, F. L. J. (2019). Sucesso na carreira na perspectiva de recémformados: Implicações para aconselhamento e gestão. Paideia, 29, 1-9. https:// doi.org/10.1590/1982-4327e2913 
Organização Internacional do Trabalho [International Labour Organization]. (2020). Youth \& COVID-19: Impacts on jobs, education, rights and mental well-being: Survey Report 2020. https://ilo.primo.exlibrisgroup.com/ discovery/fulldisplay/alma995091292902676/41ILO_INST:41ILO_V2

Reis, B. B., \& Diehl, L. (2017). Planejamento de carreira de formandos e recém-formados do ensino superior. Revista de Carreiras e Pessoas, 7(2), 564-575 https://doi.org/10.20503/recape.v7i2.32752

Upadyaya, K., \& Salmela-Aro, K. (2015). Development of early vocational behavior: Parallel associations between career engagement and satisfaction. Journal of Vocational Behavior, 90(1), 66-74. https://doi.org/10.1016/j. jvb.2015.07.008

Vieira, D. A., Caires, S., \& Coimbra, J. L. (2011). Do ensino superior para o trabalho: contributo dos estágios para a inserção profissional. Revista Brasileira de Orientação Profissional, 12(1), 29- 36. http://pepsic.bvsalud.org/ scielo.php?script=sci_arttext\&pid=S1679-33902011000100005\&lng=pt\&tlng=pt

Wendlandt, N. M. \& Rochlen, A. B. (2008). Adressing the college-to-work transition: Implications for university career counselors. Journal of Career Development, 35(2), 151-165. https://doi.org/10.1177/0894845308325646

\section{Alexandre Yomatsu de Paula Okumoto}

Graduado em Psicologia pela Universidade Federal do Triângulo Mineiro (UFTM), Uberaba - MG, Brasil.

E-mail: alexandre.okumoto@gmail.com

(1) https://orcid.org/0000-0002-4718-0104

Marina Cardoso de Oliveira

Doutora em Psicologia. Professora Adjunta do Departamento de Psicologia da Universidade Federal do Triângulo Mineiro (UFTM), Uberaba - MG, Brasil.

E-mail: mco.uftm@gmail.com

(1) https://orcid.org/0000-0002-8715-2853

\section{Lucy Leal Melo-Silva}

Doutora em Psicologia. Livre-docente e Professora Associada Sênior do Departamento de Psicologia da Universidade de São Paulo, Ribeirão Preto - SP, Brasil.

E-mail: lucileal@ffclrp.usp.br

(1) http:// orcid.org/0000-0002-5890-9896

\section{Maria do Céu Taveira}

Doutora em Psicologia da Educação. Docente e investigadora na Escola de Psicologia da Universidade do Minho, Braga, Portugal.

E-mail: ceuta@psi.uminho.pt

(D) https://orcid.org/0000-0003-1762-8702

Endereço para envio de correspondência:

Marina Cardoso de Oliveira. Universidade Federal do Triângulo Mineiro. Rua Getúlio Guaritá, 159, sala 529, Bairro Abadia. CEP: 38025-440. Uberaba - MG. Brasil.

Recebido 08/01/2020

Aceito 21/07/2021

Received $01 / 08 / 2020$

Approved 07/21/2021 
Recibido 08/01/2020

Aceptado 21/07/2021

Como citar: Okumoto, A. Y. de P., Oliveira, M. C. de, Melo-Silva, L. L., \& Taveira, M. do C. (2022). Engajamento e sucesso na transição para o trabalho: Estudo com medidas repetidas. Psicologia: Ciência e Profissão, 42, 1-14. https://doi.org/10.1590/1982-3703003232824

How to cite: Okumoto, A. Y. de P., Oliveira, M. C. de, Melo-Silva, L. L., \& Taveira, M. do C. (2022). Engagement and success during transition to work: Repeated measures study. Psicologia: Ciência e Profissão, 42, 1-14. https://doi. org/10.1590/1982-3703003232824

Cómo citar: Okumoto, A. Y. de P., Oliveira, M. C. de, Melo-Silva, L. L., \& Taveira, M. do C. (2022). Compromiso y éxito en la transición al trabajo: Estudio con medidas repetidas. Psicologia: Ciência e Profissão, 42, 1-14. https://doi.org/10.1590/1982-3703003232824 